\title{
Germicidal ultraviolet irradiation in air conditioning systems: effect on office worker health and wellbeing: a pilot study
}

\author{
Dick Menzies, Joe Pasztor, Tom Rand, Jean Bourbeau
}

\begin{abstract}
Objectives-The indoor environment of modern office buildings represents a new ecosystem that has been created totally by humans. Bacteria and fungi may contaminate this indoor environment, including the ventilation systems themselves, which in turn may result in adverse health effects. The objectives of this study were to test whether installation and operation of germicidal ultraviolet (GUV) lights in central ventilation systems would be feasible, without adverse effects, undetected by building occupants, and effective in eliminating microbial contamination.

Methods-GUV lights were installed in the ventilation systems serving three floors of an office building, and were turned on and off during a total of four alternating 3 week blocks. Workers reported their environmental satisfaction, symptoms, as well as sickness absence, without knowledge of whether GUV lights were on or off. The indoor environment was measured in detail including airborne and surface bacteria and fungi.
\end{abstract}

Results-Airborne bacteria and fungi were not significantly different whether GUV lights were on or off, but were virtually eliminated from the surfaces of the ventilation system after 3 weeks of operation of GUV light. Of the other environmental variables measured, only total airborne particulates were significantly different under the two experimental conditions-higher with GUV lights on than off. Of 113 eligible workers, 104 (87\%) participated; their environmental satisfaction ratings were not different whether GUV lights were on or off. Headache, difficulty concentrating, and eye irritation occurred less often with GUV lights on whereas skin rash or irritation was more common. Overall, the average number of work related symptoms reported was 1.1 with GUV lights off compared with 0.9 with GUV lights on.

Conclusion-Installation and operation of GUV lights in central heating, ventilation and air conditioning systems of office buildings is feasible, cannot be detected by workers, and does not seem to result in any adverse effects.

(Occup Environ Med 1999;56:397-402)

Keywords: indoor environment; indoor air pollution; indoor air quality; environmental health; building related illness; germicidal ultraviolet light
Most modern office buildings and virtually all high rise office towers have sealed exterior shells with mechanical ventilation systems. These ventilation systems are the main means by which the indoor environment is heated or cooled, humidified or dehumidified, and kept pollution free by exchange of indoor with outdoor air. Over the past 20 years, there have been numerous reports of health problems arising among workers in such buildings. ${ }^{12}$ These problems-mainly non-specific symptoms including headache, fatigue, difficulty concentrating, as well as mucosal irritative symptoms - are estimated to occur in $20 \%-$ $30 \%$ of office workers. ${ }^{34}$ Although in some cases a specific causative agent or problem is identified, in most instances no cause can be found. ${ }^{12}$

There is evidence to implicate bacteria and fungi in the pathogenesis of non-specific building related illnesses. These microorganisms have been detected in high concentrations on cooling coils, ${ }^{5}$ filters, ${ }^{6}$ drip pans, ${ }^{5}$ humidification systems, ${ }^{7}$ and in the ductwork of the supply air. ${ }^{89}$ Microbial contamination of ventilation systems has been responsible for several specific building related illnesses through toxic, allergic, hypersensitive, or infectious mechanisms. ${ }^{10}$ In five large scale cross sectional surveys involving >20 000 workers in 103 buildings, air conditioning was consistently associated with excess prevalence of non-specific building related illnesses ${ }^{11-15}$ This has been attributed to microbial contamination. ${ }^{11}$

The germicidal efficacy of ultraviolet (UV) light has been known for many decades, ${ }^{16}{ }^{17}$ and is used in hospitals, food processing plants, pharmaceutical manufacturing, and other areas where microbial decontamination is important. In the past, UV lights were not used in ventilation systems of office buildings because of technical limitations. However, newly developed high intensity lamps have overcome these limitations, making this approach feasible and safe because there would be no direct exposure to occupants of the building.

To study the efficacy of GUV lights installed in central heating, ventilation, and air conditioning (HVAC) systems, we first conducted a pilot study to assess safety, feasibility, duration of intervention periods, and possibility of detection of operation of GUV lights by building occupants. 
Methods

DESIGN

A cross over design was used. Ultraviolet lights were installed within the ventilation systems serving three floors of one downtown office building, and were turned on, or off, for a total of four alternating blocks of 3 weeks each. In the 3rd week of each block, workers completed self administered questionnaires and the indoor environment was measured in detail. Two complete sets of self administered questionnaires and environmental measurements were taken with the GUV lights off, and two sets with them on, allowing an analysis of effect within subjects.

\section{INTERVENTION}

Ultraviolet lights from three different manufacturers were installed in the ventilation systems serving separate floors of the study building (one manufacturer per floor). For manufacturer A, eight $37 \mathrm{~W}$ J-shaped bulbs which were $0.7 \mathrm{~m}$ in total length were installed. These bulbs produced UV light with an intensity of $131 \mu \mathrm{W} / \mathrm{cm}^{2}$, at a distance of $1 \mathrm{~m}$.

For manufacturer B, two bulbs $0.6 \mathrm{~m}$ long and two bulbs $0.46 \mathrm{~m}$ long were installed in each system for a total of $2.1 \mathrm{~m}$ of UV light generation. These bulbs produced $158 \mu \mathrm{W} / \mathrm{cm}^{2}$ at a distance of one metre.

For manufacturer C, $18 \mathrm{U}$ shaped bulbs, each with total length of $0.4 \mathrm{~m}$ were installed in each system. Each bulb produced UV light with an intensity of $25 \mu \mathrm{W} / \mathrm{cm}^{2}$ at a distance of one metre.

All UV bulbs produced light at $254 \mathrm{~nm}$ wavelength and were installed in the central air supply ducting just downstream from, and shining directly on the cooling coils, walls, and floor of the air supply ducting, and drip pans below the cooling coils.

\section{STUDY POPULATION}

For this pilot study, we selected a building on the basis of the characteristics of the building and ventilation system, not because of known microbial contamination, or previous problems of increased symptoms or complaints about indoor air quality. The building was an office tower constructed 15 years earlier which had a sealed exterior shell. Separate ventilation systems serving each floor had air conditioning, bag filter systems rated at $80 \%-90 \%$ efficiency, and steam humidification.

Workers were potentially eligible if their worksite was on one of the three floors served by the ventilation systems in which the UV lights were installed. We excluded workers who were not present throughout the entire study period, did not have a fixed worksite-for example, messengers or couriers-or who worked within the study building for $<2$ days a week on average-for example, sales representatives. Eligible workers who agreed to participate signed an informed consent form. This study was approved by an ethics committee of the Montreal Chest Institute Research Centre.
QUESTIONNAIRES

Before beginning the study, a baseline questionnaire was completed for demographic characteristics, personal, medical, and smoking history, as well as work and worksite characteristics. On four occasions, a weekly questionnaire was completed. This questionnaire asked respondents to indicate their environmental ratings for several variables on indoor thermal and physical comfort, and air quality. Workers reported the occurrence of symptoms that day, whether they had started since arriving at work (defined as work related), and the impact of these symptoms on their ability to work. Finally, workers were asked to indicate whether they had missed hours or days due to sickness of any type and whether they attributed any such illnesses to problems of indoor air quality.

ENVIRONMENTAL MEASURES

In the same week that the questionnaires were completed, environmental measures were taken with the following instruments and methods:

Temperature, humidity, and air velocity were measured with a direct reading VELOCICALC hot wire anometer.

Carbon dioxide was measured at the same sites and at the same times with an ADC infrared direct reading monitor.

Carbon monoxide was measured at the same times and sites as $\mathrm{CO}_{2}$ with a direct reading NEOTOX electrochemical sensor.

Total volatile organic compounds (TVOCs) were collected onto a charcoal tube with an SKC volumetric pump operating at 200 $\mathrm{ml} / \mathrm{min}$ over 8 hours, desorbed with carbon disulphide, and measured by a flame ionisation detection (FID) method-NIOSH method 1510 modified. $^{18}$

Nitrogen dioxide $\left(\mathrm{NO}_{2}\right)$ was collected with SKC volumetric air samplers operating at 75 $\mathrm{ml} / \mathrm{min}$ over 8 hours onto a solid sorbent sampling tube containing triethanolamine impregnated molecular surface and analysed with the $\mathrm{NIOSH}$ method P and CAM 231. ${ }^{18}$

Ozone $\left(\mathrm{O}_{3}\right)$ was collected by bubbling air at $1 \mathrm{l} / \mathrm{min}$ over 8 hours through an ozone absorbency solution, and analysed with NIOSH method P and CAM 154. ${ }^{18}$

Formaldehyde was collected with SKC passive samplers over an 8 hour period, analysed with the ASTM method D 5014-89. ${ }^{19}$

Total airborne dust was collected with SKC volumetric samplers operating at $1.5 \mathrm{1} / \mathrm{min}$ for 8 hours. Total dust weight was estimated by comparing dry filter weights before and after collection.

Airborne fungal colony forming units were collected with Burkhard volumetric samplers operating for 15 minutes and impacting onto Petri dishes containing Sabhourad or maltose extract agar (MEA) media. Airborne bacteria were collected with the same sampling method impacting onto blood agar (for all bacteria) and Columbia CNA (for gram positive bacteria) media. Colony forming units were counted after $48-72$ hours of growth at $37^{\circ} \mathrm{C} .^{2021}$

Surface swabs were taken from the interior walls of the main ventilation system where the 
Table 1 Data of study population (n (\%))

\begin{tabular}{lc}
\hline Participation (n): & \\
Total eligible identified & 119 \\
Refused or incomplete & 15 \\
Participants (\% of eligible) & $104(87)$ \\
Average participation each week (\% of eligible) & $97(82)$ \\
Characteristics of participants (104): & \\
Age (mean (SD)) & $45(9)$ \\
Sex (n(\%)): & \\
$\quad$ Male & $43(41)$ \\
Female & $61(59)$ \\
Smoking (currently) (n(\%)): & \\
Yes & $18(17)$ \\
$\quad$ No & $86(83)$ \\
History of atopy (n(\%)): & $37(38)$ \\
Job type (n(\%)): & $24(23)$ \\
Clerical & $80(77)$ \\
$\quad$ Management or professional & \\
\hline
\end{tabular}

UV lights were installed, cooling coils, and drip pans. The swab was dipped in a solution of $0.1 \%$ peptone with $0.01 \%$ Tween 80 , and then pulled straight along the surface for $15 \mathrm{~cm}$ at an angle of $45^{\circ}$. The swab was then rubbed in a back and forth motion covering evenly one quadrant of a Petri dish containing Sabhourad or MEA media for fungi, or blood agar plates or Columbia CNA for bacteria. The swab was discarded and a sterile loop used to spread from the edge of this first quadrant into the second quadrant, then from the edge of the second quadrant into the third quadrant, and finally, from the edge of the third into the fourth quadrant. All plates were cultured for 48 to 72 hours at $37^{\circ} \mathrm{C}$, after which colony forming units were estimated with a semiquantitative scale from 0 for no growth at all to 4 for confluent growth. Colony counts were made from the last quadrant where there was growth.

All variables were measured in outdoor air on the same days as indoor measurements were taken. Temperature, humidity, air velocity, carbon dioxide, and carbon monoxide were measured in return air and supply air of each HVAC system, as well as at the level of the ceiling diffusers and breathing zone of four randomly selected workers on each floor in the morning and afternoon of the day of completing the questionnaire (total about 300 measures of each variable). The TVOCs, $\mathrm{NO}_{2}, \mathrm{O}_{3}$, and formaldehyde were measured in supply air and at the level of ceiling diffusers and breathing zones of one worker on each floor in each week (total 40 measures of each variable). Airborne bacteria and fungi were sampled in return air, supply air, and at the level of ceiling

Table 2 Results of environmental measures under two experimental conditions

\begin{tabular}{|c|c|c|c|c|}
\hline & \multicolumn{2}{|l|}{ GUV on } & \multicolumn{2}{|l|}{ GUV off } \\
\hline & Outdoor air & Sitest & Outdoor air & Sitest \\
\hline Temperature $\left({ }^{\circ} \mathrm{C}\right)$ & 8.3 & 22.5 & 7.4 & 22.6 \\
\hline Relative humidity (\%) & 44.2 & 36.3 & 46.3 & 34.9 \\
\hline Air velocity $\left(\mathrm{m} \cdot \mathrm{s}^{-1}\right)$ & - & 0.02 & - & 0.02 \\
\hline Carbon dioxide (ppm) & 395 & 624 & 353 & 684 \\
\hline Carbon monoxide (ppm) & $<2$ & $<2$ & $<2$ & $<2$ \\
\hline TVOC $\left(\mu \mathrm{g} / \mathrm{m}^{3}\right)$ & 31 & 298 & 360 & 203 \\
\hline $\mathrm{NO}_{2}(\mathrm{ppb})$ & 0.46 & 0.30 & 0.25 & 0.18 \\
\hline Ozone (ppb) & 0.01 & 0.01 & 0 & 0 \\
\hline Formaldehyde (ppm) & 0 & 0.03 & 0.03 & 0.03 \\
\hline Total airborne particulates $\left(\mu \mathrm{g} / \mathrm{m}^{3}\right)$ & 0 & $91^{\star \star}$ & 12 & 31 \\
\hline
\end{tabular}

$\star \star \mathrm{p}<0.01$ For total airborne particulates.

†Difference in environmental variables.

-No significant difference for all variables except particulates.

GUV=germicidal ultraviolet lights. diffusers and worksites of two workers per floor (total 100 samples for each variable) and six surface swabs were taken for bacteria and fungi on each floor (total of 72 samples for variable) over the course of the study.

Ultraviolet light intensity was measured with a hand held photometer with a sensor calibrated to measure ultraviolet C (UVC) at 254 nm wavelength (International Light model No IL1400A with model SEL240 sensor).

\section{Results}

As shown in table 1, 104 of 119 (87\%) eligible workers participated-defined as completion of at least one weekly questionnaire with UV on, and at least one with UV off. Most participants were women who worked in management positions and in closed offices.

Results of environmental measures are summarised in table 2. Of particular interest, the operation of UV light did not result in increased concentrations of ozone, or TVOCs. Variation in outdoor temperature and humidity resulted in changes in indoor humidity and $\mathrm{CO}_{2}$ concentrations-because of changes in outdoor air supply. All variables were within recommended limits with the exception of total airborne particulates which were above the United States Environmental Protection Agency limits of $75 \mu \mathrm{g} / \mathrm{m}^{3}$ for 24 hour outdoor exposure on $36 \%$ of all occasions and $58 \%$ of occasions when measurements were taken with UV lights on. Airborne particulates were the only environmental contaminants that significantly increased in concentration in weeks when the GUV lights were on.

The results of fungal and bacterial cultures are shown in table 3. There was little apparent impact of operation of GUV lights on airborne microbial concentrations, although the concentrations in supply air were very low even before the UV lights were turned on, because of highly efficient bag filters used in these ventilation systems. An interesting and unexpected finding was that airborne concentrations of bacteria and fungi in the air supply was much higher when measured at the ceiling diffusers than in samples taken $10-15$ feet from the GUV lights in the central air supply ducting. This phenomenon was found in all weeks and on all floors and presumably shows recontamination from microbial growth within the duct work itself. At the level of the worksite, the bacterial concentrations were somewhat higher than at diffuser level, indicating possible human source contamination. Operation of the UV lights resulted in virtual elimination of all bacterial and fungal growth on surfaces within the HVAC system. The airborne and surface fungal and bacterial concentrations were similar on all three floors - that is, there was no detectable difference in germicidal efficacy of GUV lights produced by the three manufacturers. The intensity of GUV light, measured at the cooling coils, exceeded $550 \mu \mathrm{W} / \mathrm{cm}^{2}$ for all three manufacturers.

Surface contamination was no longer detectable in the second experimental block even 3 weeks after the UV lights were turned off, suggesting that three weeks was not sufficient time 
Table 3 Total viable (culturable) fungi and bacteria under two experimental conditions

\begin{tabular}{|c|c|c|c|c|}
\hline & \multicolumn{2}{|l|}{ Bacteria } & \multicolumn{2}{|l|}{ Fungi } \\
\hline & GUV on & GUV off & GUV on & GUV off \\
\hline \multicolumn{5}{|c|}{ Airborne $\left(\mathrm{cfu} / \mathrm{m}^{3}\right)$ : } \\
\hline Outdoor air & 135 & 58 & 50 & 6 \\
\hline Return air & 57 & 34 & 6 & 3 \\
\hline Supply air & 13 & 14 & 1 & 0 \\
\hline Diffuser & 94 & 98 & 24 & 18 \\
\hline Worksite & 100 & 132 & 34 & 23 \\
\hline \multicolumn{5}{|c|}{ HVAC surfaces (cfu/swabs): } \\
\hline Drip pans & 1.0 & 5 & 0 & 1.5 \\
\hline Cooling coils & 0.8 & 62 & 0.8 & 6.5 \\
\hline Walls & 0.3 & 5 & 0 & 1 \\
\hline
\end{tabular}

GUV=germicidal ultraviolet lights.

for recontamination to occur. This may have been because the study was conducted in October to December when outdoor microbial concentrations and humidity are low, resulting in less optimum conditions for microbial growth. After 2 months without GUV lights surface swabs showed that some recontamination had occurred by February 1998.

As shown in table 4, the weekly environmental satisfaction ratings were not different whether the UV lights were on or off. With GUV lights on, $82 \%$ of respondents thought that the ventilation system was functioning adequately to meet their needs, compared with $77 \%$ with GUV lights off. Based on all measures of workers' subjective appraisal of the indoor environment, it seemed that no worker was able to detect whether the UV lights were on or off.

Overall, $60 \%$ of workers reported some work related symptoms with the GUV lights off compared with 58\% with GUV lights on, although the average number of work related symptoms reported was about $20 \%$ lower with GUV lights on than off (table 5). There was substantial fluctuation in sickness absence from week to week; in total, with GUV lights on, $5 \%$ of workers missed some work because of illness in the preceding week, compared with $5 \%$ with GUV lights off. When GUV lights were on, no work was missed due to illnesses that the workers attributed to indoor air quality problems, whereas when the GUV lights were off, a total of 15 hours were missed in the preceding week because of such illnesses.

Table 4 Weekly environmental satisfaction ratings *

\begin{tabular}{lll}
\hline & \multicolumn{2}{l}{ Overall } \\
\cline { 2 - 3 } & GUV on & GUV off \\
\hline Questionnaires (n): & 196 & 203 \\
$\begin{array}{l}\text { Thermal comfort: } \\
\quad \text { Temperature }\end{array}$ & 3.1 & 3.2 \\
$\quad$ Humidity & 3.0 & 3.0 \\
$\quad$ Air movement & 3.2 & 3.1 \\
Physical environment: & & \\
$\quad$ Lighting & 3.4 & 3.3 \\
$\quad$ Surrounding noises & 3.6 & 3.5 \\
$\quad$ Working space & 3.6 & 3.5 \\
Indoor air quality: & & \\
$\quad$ Dust & 2.2 & 2.1 \\
$\quad$ Odours & 2.8 & 2.8 \\
$\quad$ Overall air quality & 2.5 & 2.4 \\
\hline
\end{tabular}

*All ratings scored 0 (far from ideal) to 4 (ideal). GUV=germicidal ultraviolet lights.
Table 5 Workers (\%) reporting work related symptoms under two experimental conditions

\begin{tabular}{lcc}
\hline & \multirow{2}{*}{ Overall } \\
\cline { 2 - 3 } & GUV on & GUV off \\
\hline Questionnaires completed (n) & 196 & 203 \\
Any symptoms & 58 & 60 \\
Symptoms of the CNS: & 27 & 33 \\
Headache & 15 & 20 \\
Difficulty concentrating & 14 & 14 \\
Trouble staying awake & 10 & 13 \\
Mucosal symptoms: & 42 & 44 \\
Irritated eyes & 17 & 24 \\
Dry or irritated throat & 21 & 20 \\
Dry or irritated nose & 18 & 17 \\
Stuffy, congested, or runny nose & 14 & 17 \\
Cough or difficulty breathing & 7 & 7 \\
General symptoms & 30 & 27 \\
Musculoskeletal & 13 & 14 \\
Skin rash or irritation & 22 & 15 \\
Average number of symptoms: & & \\
Not work related & 1.5 & 1.6 \\
Work related & 0.9 & 1.1 \\
Work related and reducing work & & \\
$\quad$ capacity (moderately or greatly) & 0.2 & 0.2 \\
\hline
\end{tabular}

GUV=germicidal ultraviolet lights.

\section{Discussion}

Installation and operation of GUV lights in the central HVAC system proved to be feasible. On the basis of symptoms and measurements of $\mathrm{O}_{3}$ and TVOCs, GUV lights seemed to be safe, and on the basis of environmental satisfaction the workers seemed to remain blinded. Operation of the UV lights eliminated surface bacteria and fungi, although the initial levels were low, but had no effect on airborne concentrations which were influenced more strongly by the presence of highly efficient bag filters and by apparent recontamination during passage through the supply air duct work.

Inferences from this study are limited by the few workers involved, low initial concentrations of microbial contaminants, limited microbial characterisation, and use of GUV lights produced by three different manufacturers. The small size of the study was intentional. We had calculated that a sample size of 98 participants would be required to detect with $80 \%$ power $(\beta=0.8)$, and $95 \%$ sensitivity $(\alpha=0.05)$ that the number of workers who thought that the environment was worse or unacceptable increased from $15 \%$ to $30 \% .^{22}$ In fact, more workers felt that the ventilation was acceptable with GUV lights on, than when they were off, and satisfaction ratings of indoor air quality and thermal comfort were not different. These findings suggest that there was no adverse effect on perceived indoor environmental quality and the workers remained blinded to the study intervention.

The study building was selected on the basis of HVAC characteristics of air conditioning and humidification which are risk factors for microbial contamination, ${ }^{5723}$ as well as for nonspecific building related illnesses, ${ }^{11} 12141524$ and not because it was a sick building - a very poorly defined term. ${ }^{25}$ Although it may be argued that the building should have been selected on the basis of HVAC microbial contamination, there have not been any systematic surveys of this phenomenon and therefore the concentrations of HVAC microbial contamination that can be 
considered normal or safe as opposed to hazardous, have not been defined.

There is enormous diversity and complexity of fungal and bacterial organisms which have been found in this indoor environment. This complexity of microbial flora has contributed to the difficulty in population based studies (non-outbreak situations), of detecting consistent relations between specific bacteria or fungi and occupants' symptoms of non-specific building related illnesses. The financial and logistic constraints of the present pilot study meant that characterisation of microbial contamination was crude- - being limited to counts of total viable bacteria and fungi. However, use of GUV lights as the study intervention has the advantage that GUV lights is non-specific in its germicidal action-killing a wide range of microbes, making identification less important.

We used lights produced by three different manufacturers for this pilot study. There were no significant differences in concentrations of TVOCs or ozone, nor in eradication of surface microbial contamination in the central HVAC systems between the lights produced by the three manufacturers. Given the few workers, we were unable to compare reporting of symptoms or environmental ratings between groups of workers exposed to air irradiated by the lights from the three different manufacturers.

The trend in reduction of symptoms and sickness absence in weeks when the GUV lights were operating is encouraging, but raises the question of biological plausibility. The rationale for proposing GUV lights in central HVAC systems is based on indirect evidence. (1) There is abundant evidence that exposure in the home ${ }^{10}$ or outdoor ${ }^{26-28}$ environments to the same microbes results in health effects. (2) Microbial contamination of HVAC systems has been documented, wherever there is water condensation. ${ }^{5}$ (3) Cross sectional surveys have consistently identified air conditioning as a risk factor for non-specific building related symptoms among office workers ${ }^{11} 121424$-this has been attributed to microbial contamination. ${ }^{11}$ (4) The HVAC microbial contamination has been associated with symptoms in allergic people. ${ }^{29}{ }^{30}$ (5) The HVAC microbial contamination has been implicated in many outbreaks of specific building related illness. ${ }^{123} 3132$ (6) In two well documented outbreaks, there was a wide range of manifestations. A few people had abnormalities of gas exchange, lung function, and chest radiography, but most had nonspecific symptoms, and many were asymptomatic. $^{23} 32$ All of these studies provide evidence that microbial contamination could be responsible for non-specific symptoms. These would probably be labelled as sick building syndrome if there were no sentinel case with objective health effects which indicated that a specific building related illnesses existed. On the other hand, several cross sectional surveys in non-problem buildings or non-outbreak situations have failed to detect any relation between fungal concentrations and occupants' symptoms.

We hypothesise that microbial contamination of central HVAC systems may play an important part in the pathogenesis of nonspecific building related illnesses. Source control remains the most important method of prevention of such illnesses. However, if source control measures have failed or as an adjunct measure, germicidal ultraviolet lights are a relatively low cost intervention that could eradicate this contamination. Our study has shown that it is feasible to install and operate these GUV lights in existing ventilation systems without detection or adverse effects among workers. These findings plus a trend to reduction in symptoms support the need for a larger scale study of GUV lights involving more workers in more buildings.

For this type of study, buildings must be selected on the basis of risk factors for microbial contamination, which include air conditioning, ${ }^{523}$ humidification, ${ }^{5}$ low efficiency filters, ${ }^{30}$ poor cleaning and maintenance, ${ }^{33}$ or evaporative type of humidification. ${ }^{14}{ }^{24}$ As well, the study design must incorporate longer cross over periodsthat is, more time between periods of operation of GUV lights, because in this pilot study 2 months was required for recontamination to occur. Such longer intervals would have the potential disadvantage of greater losses to the study population, but may result in less reduction in symptoms over time-a problem noted in this and other short term cross over studies. ${ }^{34}$ If such a study showed a considerable beneficial effect of GUV light, then this technology, which is safe and relatively low cost, could be installed in existing buildings throughout North America. Also, such a result would provide further evidence for the causal role of microorganisms in the pathogenesis of non-specific illnesses related to buildings.

We thank owners, management, and workers in the study buildings for their collaboration and participation. We acknowledge Inspiraplex - The Respiratory Health Network of Centres of Excellence for funding the pilot study, as well as Clean Air Concepts, FP Technologies, and Sanuvox for provision of germicidal ultraviolet light equipment. DM was supported by a medical scientist award from the Medical Research Council of Canada. JB was supported by a clinician scientist award from the Fonds de la Recherche en Santé du Québec.

1 Menzies D, Bourbeau J. Building-related illnesses. $N$ Engl f Med 1997;337:1524-31.

2 Samet JM, Marbury MC, Spengler JD. Health effects and sources of indoor air pollution. Am Rev Respir Dis 1988;137:221-42.

3 Mendell $M$. Non-specific symptoms in office workers: a review and summary of the literature. Indoor Air 1993;B: $227-36$.

4 Woods JE. Cost avoidance and productivity in owning and operating buildings. Occup Med 1989;4:753-70.

5 Hugenholtz P, Fuerst JA. Heterotrophic bacteria in an air-handling system. Appl Environ Microbiol 1992;58:391420 .

6 Neumeister H, Moritz M, Schleibinger $\mathrm{H}$, et al. Investigation of allergic potential induced by fungi on air filters of tion of allergic potential induced by fungi
HVAC systems [abstract]. 1996;3:125-30.

7 Burge PS, Finnegan MJ, Horsfield N, et al. Occupational asthma in a factory with a contaminated humidifier. Thorax $1985 ; 40: 248-54$

8 Smoragiewicz W, Cossette B, Boutard A, et al. Trichothecene mycotoxins in the dust of ventilation systems in office buildings [abstract]. Int Arch Occup Environ Health 1993;65:113-17.

9 Pasanen P, Pasanen AL, Jantunen M. Water condensation promotes fungal growth in ventilation ducts. Indoor Air 1993;3:106-112

10 Husman T. Health effects of indoor-air microorganisms. Scand $\mathcal{F}$ Work Environ Health 1996;22:5-13.

11 Mendell MJ, Smith AH. Consistent pattern of elevated symptoms in air-conditioned office buildings: a re-analysis symptoms in air-conditioned office buildings: a re-analysis
of epidemiologic studies. Am $\mathcal{F}$ Public Health 1990;80: of epidemic $1193-9$. 
12 Mendell MJ, Fisk WJ, Deddens JA, et al. Elevated symptom prevalence associated with ventilation type in office prevalence associated with ventilation
buildings. Epidemiology 1996;7:583-9.

13 Salvaggio JE. Recent advances in the pathogenesis of allergic alveolitis. Clin Exp Allergy 1990;20:137-44.

14 Zweers T, Preller L, Brunekreef B, et al. Health and indoor climate complaints of 7043 office workers in 61 buildings in The Netherlands. Indoor Air 1992;2:127-36.

15 Harrison J, Pickering CA, Faragher EB, et al. An investigation of the relationship between microbial and particulate indoor air pollution and the sick building syndrome. Respir Med 1992;86:225-35

16 Riley RL, Knight M, Middlebrook G. Ultraviolet susceptibilty of BCG and virulent tubercule baccilli. Am Rev Respir Dis 1976;113:413-8.

17 Riley RL, O'Grady FO. Airborne infection: transmission and control. New York: Macmillan, 1961.

18 National Institute for Occupational Safety and Health. Manual of analytical methods, 2nd ed [abstract]. Cincinnati: NIOSH, 1977 .

19 American Society of Testing Materials. ASTM standard test method for measurement of formaldehyde in indoor air (passive sampler methodology). In: American Society of Testing Materials, ed. Occupational health and safety. Philedelphia, PA: ASTM, 1990;425-30.

20 American Conference of Governmental Industrial Hygenists. Guidelines for assessment and sampling of saprophytic bioaerosols in the indoor environment. Appl Ind Hyg 1987; 2:R10-16.

21 Lavoie J, Lazure L. Guide for prevention of microbial growth in ventilation systems [abstract]. 1994

22 Dawson-Saunders B, Trapp RG. Basic and clinical biostatistics. Norwalk: Appleton and Lange, 1990.

23 Bernstein RS, Sorenson WG, Garabrant D, et al. Exposures to respirable, airborne Penicillium from a contaminanted ventilation system: clinical, environmental, and epidemiologic aspects. Am Ind Hyg Assoc 7 1983;44:161-9.
24 Jaakkola JJK, Miettinen P. Type of ventilation system in office buildings and sick building syndrome. $A m \quad \mathcal{F}$ Epidemiol 1995;141:755-65.

25 Hodgson M. The sick-building syndrome. Occup Med 1995; 10:167-75.

26 Neas LM, Dockery DW, Burge H, et al. Fungus spores, air pollutants, and other determinants of peak expiratory flow rate in children. Am f Epidemiol 1996;143:797-807.

27 O'Hollaren MT, Yunginger W, Offord KP, et al. Exposure to an aeroallergen as a possible precipitating factor in respiratory arrest in young patients with asthma. $N$ Engl $\mathcal{F} M e d$ 1991;324:359-63.

28 Salvaggio J. Mould induced asthma. f Allergy Clin Immunol $1981 ; 68: 327-46$

29 Elixmann JH, Schata M, Jorde W. Fungi in filters of air-conditioning systems cause the building related illness [abstract]. 1990;1:193-5.

30 Menzies D, Comtois P, Pasztor J, et al. Aeoallergens and work-related respiratory symptoms among office workers. $\mathcal{F}$ Allergy Clin Immunol 1998;101:38-44.

31 Pelaz C, Martin-Bougon C. Characterization of clinical and environmental isolates of legionella associated with outbreaks and study of infectious sources. Infectiosas $y$ Microbiologia Clinica 1993;11:359-65.

32 Woodard ED, Friedlander B, Lesher RJ, et al. Outbreak of hypersensitivity pneumonitis on an industrial setting. 7AMA 1988;259:1965-9.

33 Sieber WK, Stayner LT, Malkin R, et al. The National Institute for occupational safety and health indoor environmental evaluation experience. Part three: associations between environmental factors and self-reported health conditions. Appl Occup Environ Hyg 1996;11:1387-92.

34 Menzies RI, Tamblyn RM, Farant JP, et al. The effect of varying levels of outdoor air supply on the symptoms of sick building syndrome. $N$ Engl f Med 1993;328:821-7.

\section{Rejected manuscripts}

From February 1994, authors whose submitted articles are rejected will be advised of the decision and one copy of the article, together with any reviewer's be returned to them. The fournal will destroy remaining copies of the article but correspondence and reviewers' comments will be kept. 